\title{
Canadian physicians' choices for their own colon cancer screening
}

\author{
Mamoon Raza MD, Charles N Bernstein MD FRCPC, Alexandra Ilnyckyj MD FRCPC
}

M Raza, CN Bernstein, A Ilnyckyj. Canadian physicians' choices for their own colon cancer screening. Can J Gastroenterol 2006;20(4):281-284.

INTRODUCTION: Compliance with colorectal cancer (CRC) screening in Canada is low. The aim of the present survey was to determine whether Canadian physicians older than 50 years were pursuing colon cancer screening. Specifically, physicians were asked to identify their modality of choice and identify their barriers to screening.

METHODS: Surveys were mailed to members, older than 50 years, of the Canadian Association of Gastroenterology, the Society of Obstetricians and Gynaecologists of Canada, the Canadian Society of Internal Medicine, the Canadian Psychiatric Association and the Canadian Association of Radiologists.

RESULTS: Of 2807 surveys, 46\% were returned. Screening for CRC was reported by $53 \%$ of respondents. The Canadian Association of Radiologists members (61\%) and the Canadian Association of Gastroenterology members (61\%) were more likely to be screened than other specialties $(\mathrm{P}<0.01$ and $\mathrm{P}<0.05$, respectively). Members of the Society of Obstetricians and Gynaecologists of Canada (44\%) were least likely to be screened $(\mathrm{P}<0.001)$. Men $(\mathrm{P}<0.001)$ and Ontario physicians $(\mathrm{P}<0.01)$ were more likely to be screened than women and Canadian physicians from other provinces, respectively. Colonoscopy (56\%) was the most common screening modality used, followed by fecal occult blood testing (27\%). Respondents who had not been screened cited a lack of personal time (47\%) and insufficient data to warrant screening (14\%).

DISCUSSION: More than one-half of all respondents were screened for CRC. Colonoscopy is the most common screening modality used. Lack of time is the most common reason cited for not participating in CRC screening.

\section{Choix des médecins au Canada quant à leur propre dépistage du cancer du côlon}

INTRODUCTION : Le dépistage du cancer colorectal (CCR) se fait de façon plus ou moins systématique au Canada. La présente enquête visait à déterminer si les médecins âgés de plus de 50 ans, au Canada, se soumettaient au dépistage du cancer du côlon. Plus précisément, on leur a demandé quels étaient leur méthode préférée de dépistage et les obstacles au dépistage.

MÉTHODE : Des questionnaires ont été envoyés par la poste à des membres âgés de plus de 50 ans, appartenant aux organisations suivantes : l'Association canadienne de gastroentérologie, la Société des obstétriciens et gynécologues du Canada, la Société canadienne de médecine interne, l'Association des psychiatres du Canada et l'Association canadienne des radiologistes.

RÉSULTATS : Nous avons envoyé 2807 questionnaires et, de ce nombre, $46 \%$ ont été retournés. Cinquante-trois pour cent des répondants ont déclaré s'être soumis au dépistage du CCR. Les membres de l'Association canadienne des radiologistes $(61 \%)$ et de l'Association canadienne de gastroentérologie $(61 \%)$ se sont soumis plus souvent que les autres au dépistage $(\mathrm{P}<0,01$ et $\mathrm{P}<0,05$, respectivement), et les membres de la Société des obstétriciens et gynécologues du Canada (44\%) sont ceux qui s'y sont soumis le moins $(\mathrm{P}<0,001)$. Les hommes $(\mathrm{P}<0,001)$ et les médecins en Ontario $(\mathrm{P}<0,01)$ étaient plus susceptibles de faire l'objet de dépistage que les femmes et les médecins des autres provinces, respectivement. La coloscopie (56\%) était la méthode privilégiée de dépistage, suivie de la recherche de sang occulte dans les selles (27\%). Les répondants qui ne se sont pas prêtés au dépistage ont invoqué le manque de temps $(47 \%)$ et le manque de données à l'appui du dépistage (14\%).

DISCUSSION : Plus de la moitié des répondants ont fait l'objet de dépistage du CCR. La coloscopie s'est avérée le moyen privilégié de dépistage. Enfin, le manque de temps a été le motif le plus souvent invoqué pour ne pas participer au dépistage du CCR.

Key Words: Colon cancer; Screening

Colorectal cancer (CRC) is the third most common form of malignancy and is the second leading cause of cancerrelated deaths among Canadian men and women (1). CRC screening by fecal occult blood testing (FOBT), with follow-up colonoscopy when indicated, has led to a reduction in mortality (2-4) and colonoscopy with polypectomy has led to a reduction in the incidence of CRC (5).

In 2001, the Canadian Task Force for Preventive Health recommended the inclusion of FOBT or flexible sigmoidoscopy (FS) in the periodic health examination (6). In the recommendations for the periodic health examination, the Task Force concluded that there was insufficient evidence to include or exclude a colonoscopy.
The Canadian Association of Gastroenterology (CAG) published their most recent guidelines regarding $\mathrm{CRC}$ screening in February 2004 (7). In addition to biennial FOBT and FS every five years, they recommended colonoscopy every 10 years as an appropriate option for screening patients at average risk.

Therefore, screening average risk patients may include annual or biennial FOBT, FS every five years, double contrast barium enema (DCBE) every five to 10 years or colonoscopy every 10 years.

There are no national estimates of CRC screening rates in Canada. It has been reported that $20 \%$ of eligible 50 to 59 year olds in Ontario, without CRC or inflammatory bowel disease, have undergone any one of the tests available for CRC 
TABLE 1

Response rate by organization

\begin{tabular}{lcc}
\hline Organization & $\begin{array}{c}\text { Mailings, } \\
\mathbf{n}\end{array}$ & $\begin{array}{c}\text { Responses, } \\
\mathbf{n}(\%)\end{array}$ \\
\hline Overall & 2807 & $1291(46)$ \\
Canadian Association of Radiologists & 960 & $361(38)$ \\
Society of Obstetricians and Gynaecologists of Canada & 616 & $283(46)$ \\
Canadian Association of Gastroenterology & 446 & $294(66)$ \\
Canadian Society of Internal Medicine & 271 & $136(50)$ \\
Canadian Psychiatric Association & 512 & $217(42)$ \\
\hline
\end{tabular}

screening $(8,9)$. In the United States, recent national screening rates for any endoscopic modality have been reported at $48.1 \%$, (range $30 \%$ to $64 \%$ ) (10).

Our study aimed to determine how Canadian physicians are interpreting recommendations regarding CRC screening. We explored this by undertaking a survey examining personal preferences for CRC screening among target age Canadian specialists. Interspecialty, age, sex and geographical variables were examined. We also explored respondents' reasons for not participating in CRC screening.

\section{METHODS}

Membership mailing lists were requested from five professional societies, representing Canadian specialists, to facilitate a survey. The specialist groups were selected to reflect a broad range of physicians. The Canadian Society of Internal Medicine, the CAG, the Society of Obstetricians and Gynaecologists of Canada, the Canadian Psychiatric Association and the Canadian Association of Radiologists agreed to participate in the study.

A database of registered Canadian physicians older than 50 years was obtained from each organization (CAG excluded) and a 10 question survey was mailed along with a cover letter, consent information and a postage paid return envelope. The surveys were anonymous and colour coded to represent each specialty. The CAG database does not sort by age and, hence, the survey was mailed to all members. CAG members younger than 50 years were excluded from analysis of anything other than response rates.

The survey asked the physician whether they had undergone CRC screening and, if so, by which method. Respondents who had not been screened were asked to indicate their reason(s) from a list:

- don't think there are sufficient data to warrant screening;

- concerned about physical discomfort during endoscopy;

- don't want to incur potential risks of endoscopy;

- time constraints, but I am meaning to do it;

- concerned about psychological distress during endoscopy; and

- other.

All participants were asked about compliance with preventive health measures, specifically mammography, Papanicolaou smear, blood pressure monitoring, cholesterol monitoring and hepatitis vaccination. Those who indicated that they had pursued two or more of these measures were defined as compliers with preventive health care.
TABLE 2

Respondent demographics

\begin{tabular}{lccc}
\hline Organization & Men, $\mathbf{n}(\%)$ & $\begin{array}{c}\mathbf{5 0 - 6 4} \text { years } \\
\text { of age, } \mathbf{n}(\%)\end{array}$ & $\begin{array}{c}\geq 65 \text { years } \\
\text { of age, } \mathbf{n}(\%)\end{array}$ \\
\hline Overall & $1075(83)$ & $765(70)$ & $335(30)$ \\
CAR & $310(86)$ & $199(56)$ & $159(44)$ \\
SOGC & $214(76)$ & $245(87)$ & $38(13)$ \\
CAG & $247(84)$ & $122(86)$ & $20(14)$ \\
CSIM & $118(87)$ & $105(81)$ & $24(19)$ \\
CPA & $186(86)$ & $94(50)$ & $94(50)$ \\
\hline
\end{tabular}

CAG Canadian Association of Gastroenterology; CAR Canadian Association of Radiologists; CPA Canadian Psychiatric Association; CSIM Canadian Society of Internal Medicine; SOGC Society of Obstetricians and Gynaecologists of Canada

Each response was entered into a confidential database and results were analyzed by descriptive analysis. Statistical significance was determined by the $\chi^{2}$ test.

The study was approved by the Research Ethics Board at the University of Manitoba, Faculty of Medicine (Winnipeg, Manitoba).

\section{RESULTS}

Of the 2807 surveys mailed out, 1291 were returned (46\%) (Table 1). Of 1291 respondents, 1075 (83\%) were men. Thirty per cent of respondents were older than 65 years (Table 2). Of 1291 respondents, 162 were younger than 50 years, and eight of 1291 did not return a complete survey. The remaining 1121 respondents were older than 50 years and constitute the survey sample.

\section{Screening rates}

Fifty-three per cent of respondents had been screened for CRC, and screening rates varied by specialty. Canadian Association of Radiologists members (220 of 358 [61\%]) and CAG members (86 of $140[61 \%]$ ) were more likely to be screened than the other specialties $(\mathrm{P}<0.01$ and $\mathrm{P}=0.041$, respectively). Society of Obstetricians and Gynaecologists of Canada members (123 of 282 [44\%]) and Canadian Society of Internal Medicine members (61 of 136 [45\%]) were least likely to be screened $(\mathrm{P}<0.001$ and $\mathrm{P}=0.008$, respectively). Men were more likely to be screened than women (524 of 943 [56\%] versus 72 of 177 [41\%], $\mathrm{P}<0.001)$ and the likelihood of screening increased with age $(\mathrm{P}<0.001)$. Screening rates also varied by province. Physicians in Ontario were more likely to have undergone CRC screening than those in the rest of Canada (239 of 406 [59\%] versus 357 of 714 [50\%], P=0.005), while physicians in the Maritimes were less likely to have undergone screening (38 of 93 [41\%] versus 558 of 1027 [54\%], $\mathrm{P}=0.017$ ).

\section{Screening modality}

Colonoscopy was the most common screening modality used $(56 \%)$ and FOBT was the second most common modality $(27 \%)$. Fewer than $15 \%$ of respondents used FS, DCBE or a combination of FS and FOBT as their initial modality. The questionnaire accounted for those who had a colonoscopy in response to a positive FOBT; hence, the colonoscopy rates represent only those who chose colonoscopy as their primary screening modality. 
TABLE 3

Choice of initial screening modality by specialty, sex and age

\begin{tabular}{|c|c|c|c|c|c|}
\hline & $\begin{array}{c}\text { Colonoscopy, } \\
\text { n (\%) }\end{array}$ & $\begin{array}{l}\text { FOBT, } \\
\text { n (\%) }\end{array}$ & $\begin{array}{c}\text { FS, } \\
\text { n (\%) }\end{array}$ & $\begin{array}{l}\text { FOBT and } \\
\text { FS, n (\%) }\end{array}$ & $\begin{array}{l}\text { DCBE, } \\
\text { n (\%) }\end{array}$ \\
\hline Overall $^{*}, \mathrm{n}=594$ & $335(56)$ & $160(27)$ & $35(6)$ & $15(3)$ & $34(6)$ \\
\hline \multirow[t]{2}{*}{$\mathrm{CAR}^{*}, \mathrm{n}=216$} & $96(44)$ & $61(28)$ & $11(5)$ & $5(2)$ & $29(13)$ \\
\hline & & & & & $P<0.001 \dagger$ \\
\hline SOGC, $n=123$ & $75(61)$ & $33(27)$ & $9(7)$ & $4(3)$ & $2(2)$ \\
\hline \multirow[t]{2}{*}{ CAG, $n=86$} & $78(91)$ & $4(5)$ & $3(3)$ & 0 & $1(1)$ \\
\hline & $P<0.001^{\dagger}$ & $P<0.001^{\dagger}$ & & & \\
\hline $\operatorname{CSIM}, \mathrm{n}=59$ & $37(63)$ & $17(29)$ & $4(7)$ & $1(2)$ & 0 \\
\hline \multirow[t]{2}{*}{ CPA, $n=108$} & $49(45)$ & $44(41)$ & $8(7)$ & $5(5)$ & $2(2)$ \\
\hline & & $\mathrm{P}=0.009^{\dagger}$ & & & \\
\hline$M_{e n}^{*}, n=523$ & $299(57)$ & $134(26)$ & $35(7)$ & $15(3)$ & $26(5)$ \\
\hline Women ${ }^{*}, \mathrm{n}=72$ & $36(51)$ & $26(37)$ & $1(1)$ & 0 & $8(11)$ \\
\hline \multicolumn{6}{|c|}{ Age 50-64 years*, } \\
\hline \multirow[t]{2}{*}{$n=379$} & $234(62)$ & $95(25)$ & $20(5)$ & $5(1)$ & $21(6)$ \\
\hline & $\mathrm{P}=0.0011^{\ddagger}$ & & & & \\
\hline \multicolumn{6}{|l|}{ Age $\geq 65$ years $^{\star}$} \\
\hline $\mathrm{n}=215$ & $101(47)$ & $65(30)$ & $15(7)$ & $10(5)$ & $13(6)$ \\
\hline
\end{tabular}

*14 male and 1 female Canadian Association of Radiologists (CAR) members indicated both flexible sigmoidoscopy (FS) and barium enema (BE) as the modality they chose for screening and were excluded, overall $=15, C A R=202$, men $=509$, women $=1$, age 50-74 $=4$, age greater than $65=11 ;{ }^{\dagger}$ Compared with overall rate for respective modality; $¥$ Compared with respondents 65 years of age or older. CAG Canadian Association of Gastroenterology; CPA Canadian Psychiatric Association; CSIM Canadian Society of Internal Medicine; DCBE Double contrast BE; FOBT Fecal occult blood test: SOGC Society of Obstetricians and Gynaecologists of Canada

\section{Specialty}

Choice of screening test varied with specialty, sex and age (Table 3). CAG members were more likely to be screened with colonoscopy (78 of 86 [91\%] versus 257 of 495 [52\%], $\mathrm{P}<0.001$ ) and less likely to be screened with FOBT (four of 86 [5\%] versus 154 of 508 [30\%], $\mathrm{P}<0.001$ ) than the overall group. Canadian Psychiatric Association members were more likely to have a FOBT as their initial screening test (44 of 108 [41\%] versus 116 of 486 [24\%], $\mathrm{P}=0.009$ ) and Canadian Association of Radiologists members were more likely to have a DCBE than other specialties (29 of 217 [13\%] versus five of 377 [1\%], $\mathrm{P}<0.001)$.

\section{Age and sex}

Physicians who were between 50 and 64 years of age were more likely to be screened with colonoscopy than those older than 65 years (234 of 379 [62\%] versus 101 of 215 [47\%], $\mathrm{P}=0.0011$ ). There was a trend toward male physicians screening with colonoscopy compared with female physicians; however, this did not reach statistical significance (299 of 524 [57\%] versus 36 of 71 [51\%], not significant). However, for each variable examined, colonoscopy remained the most common screening modality.

\section{Region}

The choice of initial screening modality also varied by province (Table 4). In Quebec, physicians were more likely to be screened with DCBE (18 of 114 [16\%] versus 16 of 480 [3\%], $\mathrm{P}<0.001$ ) and less likely to be screened with FOBT (14 of 114 [12\%] versus 146 of 480 [30\%], $\mathrm{P}<0.001$ ) than specialists in the rest of Canada. Physicians in British Columbia had less
TABLE 4

Choice of initial screening modality by province or region

\begin{tabular}{lccccc}
\hline $\begin{array}{l}\text { Province or } \\
\text { region (n) }\end{array}$ & $\begin{array}{c}\text { Colonoscopy, } \\
\mathbf{n}(\%)\end{array}$ & $\begin{array}{c}\text { FOBT, } \\
\mathbf{n}(\%)\end{array}$ & $\begin{array}{c}\text { FS, } \\
\mathbf{n}(\%)\end{array}$ & $\begin{array}{c}\text { FOBT and } \\
\text { FS, } \mathbf{n}(\%)\end{array}$ & $\begin{array}{c}\text { DCBE, } \\
\mathbf{n}(\%)\end{array}$ \\
\hline Overall* (594) & $335(56)$ & $160(27)$ & $35(6)$ & $15(3)$ & $34(6)$ \\
British Columbia & $22(38)$ & $20(34)$ & $7(12)$ & $4(7)$ & $4(7)$ \\
$\quad(58)$ & $\mathrm{P}=0.0028^{\dagger}$ & & $\mathrm{P}=0.035^{\dagger}$ & & \\
Alberta (53) & $28(53)$ & $19(36)$ & $3(6)$ & $2(4)$ & 0 \\
Saskatchewan (12) & $8(67)$ & $3(25)$ & 0 & 0 & $1(8)$ \\
Manitoba (74) & $40(54)$ & $26(35)$ & $3(4)$ & $2(3)$ & $1(1)$ \\
Ontario (238) & $140(59)$ & $65(27)$ & $13(5)$ & $3(1)$ & $9(4)$ \\
Quebec (114) & $73(64)$ & $14(12)$ & $5(4)$ & $3(3)$ & $18(16)$ \\
& & $\mathrm{P}<0.001^{\dagger}$ & & & $\mathrm{P}<0.001^{\dagger}$ \\
Maritimes (38) & $24(63)$ & $7(18)$ & $4(11)$ & 0 & $1(3)$ \\
\hline
\end{tabular}

*15 Canadian Association of Radiologists members from various provinces indicated both flexible sigmoidoscopy (FS) and barium enema (BE) as the modality they chose for screening and were excluded, overall $=15$, British Columbia $=1$, Alberta $=1$, Manitoba $=2$, Ontario $=8$, Quebec $=1$, Maritimes $=2$; ${ }^{\dagger}$ Compared with overall rate for respective modality. $D C B E$ Double contract BE; FOBT Fecal occult blood test

colonoscopy screening (22 of 58 [38\%] versus 313 of 536 [58\%], $\mathrm{P}=0.0028$ ) and more $\mathrm{FS}$ screening (seven of 58 [12\%] versus 28 of 536 [5\%], $\mathrm{P}=0.035$ ) than other Canadian physicians. However, colonoscopy was the most common screening modality used in all provinces.

\section{Screening interval}

Of 335 respondents who had a screening colonoscopy, 305 (91\%) would prefer to continue screening with this modality. Of those, $85 \%$ would choose to be rescreened in five years or sooner, and the remaining $15 \%$ would like to be screened at 10 -year intervals.

\section{Nonscreened respondents}

Of the physicians who had not been screened for colon cancer and provided us with a reason as to why not $(\mathrm{n}=472)$, the most commonly cited reason (49\%) was a lack of time with an intent to pursue screening in the future. Only 14\% (159 of 1121) of all respondents thought there were not enough data to warrant screening (34\% of the not screened group, 159 of 472). Other reasons for not being screened included physical discomfort (5\%), concerns over complications at endoscopy $(7 \%)$, that it had not been mentioned or recommended by their primary care physician (3\%) or they had not given consideration to the issue (2\%).

\section{Compliers}

Applying our definition of compliance, those who were compliant with other preventive health measures were more likely to have been screened for CRC as opposed to those who were not (524 of 904 [58\%] versus 72 of 217 [33\%], $\mathrm{P}<0.001$ ).

\section{DISCUSSION}

Our study shows that over one-half of Canadian specialists older than 50 years are undergoing CRC screening. Colonoscopy is the most common screening modality employed regardless of physician age, sex, specialty and region. Almost all physicians who underwent colonoscopic screening would prefer to continue using this modality for future screening and most would like to be rescreened at five year intervals or less. 
Despite the recommendations of the Canadian Task Force for Preventive Health for FS as a first-line test for screening (6), fewer than $10 \%$ of screened Canadian specialists chose this modality, either alone or in combination with FOBT. Of those in the target age range who have not yet undergone screening, one-half cited a lack of time as their limitation and $77 \%$ of those would chose colonoscopy as their screening modality. A lack of evidence supporting screening was an uncommon reason for not participating.

Our study suggests that the screening rate among Canadian specialists in the target age range is higher than the rate reported in the literature for the general population $(8,9)$. If respondents who cited "time constraints but I am meaning to do it" are considered, then $73 \%$ of Canadian specialists comply or intend to comply with CRC screening. This attitude toward screening is not limited to those specialists who arguably may have a heightened awareness of colon cancer, ie, gastroenterologists or radiologists, but crosses a wide spectrum of physicians.

In a recent survey of Alberta physicians, including family physicians, gastroenterologists and general surgeons, 58\% stated that they recommend CRC screening to their average-risk patients older than 50 years (11). Although the overall rate mirrors our study's findings, only 26\% recommended colonoscopy as the initial screening modality, whereas $79 \%$ recommended FOBT. It is important to emphasize that this study examined the primary care physician's recommendation to patients rather than the personal choice of specialists. These study variables likely explain the different results.

A weakness of our study is the lack of respondent stratification with respect to personal CRC risk. It is possible that respondents to this survey were a select group of individuals at higher than average risk for CRC. Thus, their choice of a colonoscopy as a first-line modality and selecting a screening interval of five years may reflect compliance with recommendations for high-risk patients. We speculate the effect of this potential factor to be small because physicians are not at increased risk of cancer.

It may be that the relatively high screening rates found in our study are a result of the greater likelihood that physicians who are compliant with screening recommendations would respond to surveys. Our survey tracked compliance with other health preventive measures (hepatitis and other vaccinations, breast and cervical cancer screening, blood pressure and lipid level determinations) and, indeed, a greater number of those undergoing CRC screening were compliers with preventive health care measures. Despite this, specialist uptake of CRC screening is very high compared with the general population. Variables such as sex and knowledge about CRC have been shown to be important among eligible adults in the United States $(12,13)$ and may partly explain the high screening rate documented in the present study.

Of greater interest is that specialists seem to favour and pursue the most aggressive approach to CRC screening. Do they believe other screening strategies that are promoted to Canadians by the Canadian Task Force for Preventive Health to be inadequate? Why are they accessing resources that are scarce (7), and nonreimbursable in some jurisdictions, for average risk screening?

The Quebec Association of Gastroenterologists has recently responded to these challenging questions (14). The task force stated, with respect to the role of colonoscopy in CRC screening, that higher quality data are not forthcoming. Thus, a screening program with colonoscopy is called for with designated tariffs for reimbursement. The general public and primary caregiver in Quebec have been given clear directives on screening strategy. If provincial and national health authorities adopt the recommendations of the Quebec Association of Gastroenterologists, then policy will reflect what appears to be Canadian specialist practice for personal health care.

ACKNOWLEDGEMENTS: The authors thank the national physician organizations whose collegial cooperation made this study possible. Dr Charles Bernstein is supported in part by a Canadian Institutes of Health Research Investigator Award and a Crohn's and Colitis Foundation of Canada Research Scientist Award. Dr Ilnyckyj is supported in part by AstraZeneca Canada.

\section{REFERENCES}

1. National Cancer Institute of Canada. Canadian Cancer Statistics 2004. Toronto: NCIC, 2004.

2. Mandel JS, Church TR, Bond JH, et al. The effect of fecal occult-blood screening on the incidence of colorectal cancer. N Engl J Med 2000;343:1603-7.

3. Mandel JS, Bond JH, Church TR, et al. Reducing mortality from colorectal cancer by screening for fecal occult blood. Minnesota Colon Cancer Control Study. N Engl J Med 1993;328:1365-71. (Erratum 1993;329:672).

4. Mandel JS, Church TR, Ederer F, Bond JH. Colorectal cancer mortality: Effectiveness of biennial screening for fecal occult blood.

J Natl Cancer Inst 1999;91:434-7.

5. Winawer SJ, Zauber AG, Ho MN, et al. Prevention of colorectal cancer by colonoscopic polypectomy. N Engl J Med 1993;329:1977-81.

6. Canadian Task Force on Preventive Health Care. Colorectal cancer screening. Recommendation statement from the Canadian Task Force on Preventive Health Care. CMAJ 2001;165:206-8.

7. Leddin D, Hunt R, Champion M, et al. Canadian Association of Gastroenterology and the Canadian Digestive Health Foundation: Guidelines on colon cancer screening. Can J Gastroenterol 2004;18:93-9.

8. Rabeneck L, Paszat LF. A population-based estimate of the extent of colorectal cancer screening in Ontario. Am J Gastroenterol 2004;99:1141-4.

9. Singh SM, Paszat LF, Li C, He J, Vinden C, Rabeneck L. Association of socioeconomic status and receipt of colorectal cancer investigations: A population-based retrospective cohort study. CMAJ 2004;171:461-5.

10. Balluz L, Ahluwalia IB, Murphy W, Mokdad A, Giles W, Harris VB. Surveillance for certain health behaviors among selected local areas United States, Behavioral Risk Factor Surveillance System. MMWR Surveill Summ 2004;53:1-100.

11. Mack LA, Stuart H, Temple WJ. Survey of colorectal cancer screening practices in a large Canadian urban centre. Can J Surg 2004;47:189-94.

12. Weinberg DS, Turner BJ, Wang H, Myers RE, Miller S. A survey of women regarding factors affecting colorectal cancer screening compliance. Prev Med 2004;38:669-75.

13. Stokamer CL, Tenner CT, Chaudhuri J, Vazquez E, Bini EJ. Randomized controlled trial of the impact of intensive patient education on compliance with fecal occult blood testing. J Gen Intern Med 2005;20:278-82.

14. Barkun AN, Jobin G, Cousineau G, et al. The Quebec Association of Gastroenterology position paper on colorectal cancer screening - 2003. Can J Gastroenterol 2004;18:509-19. (Erratum 2004;18:591). 


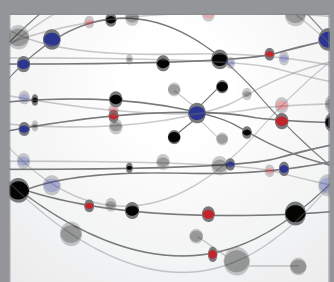

The Scientific World Journal
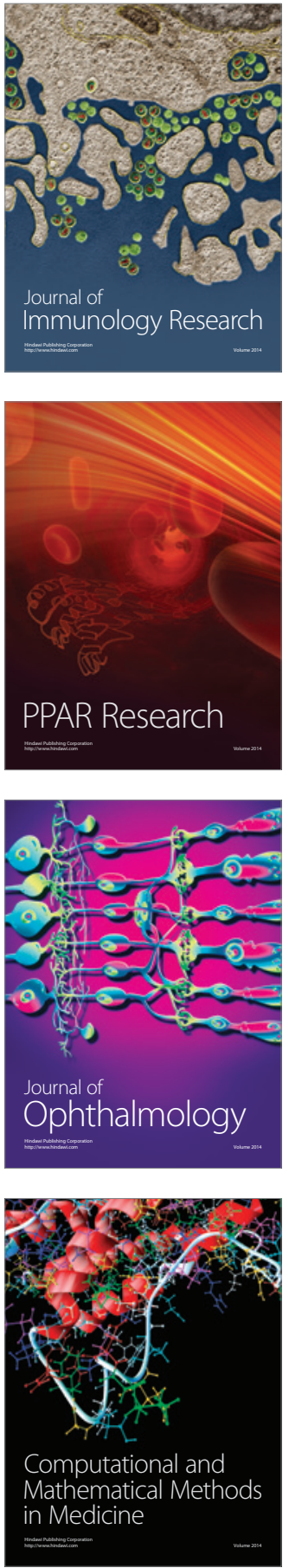

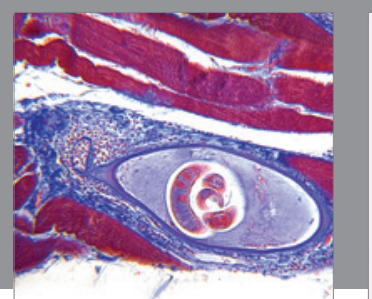

Gastroenterology Research and Practice

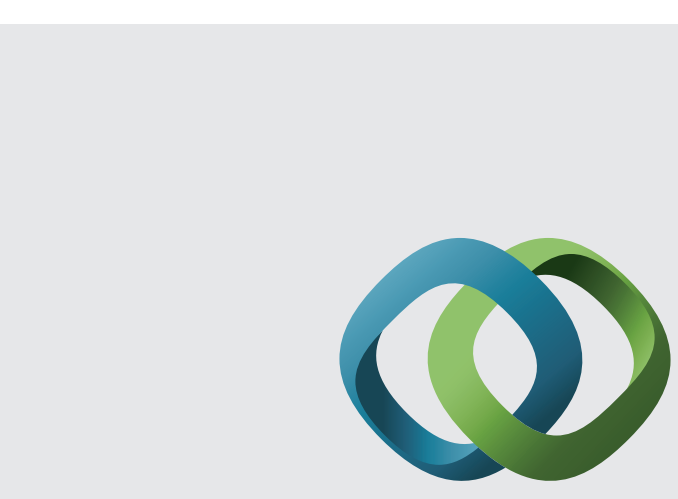

\section{Hindawi}

Submit your manuscripts at

http://www.hindawi.com
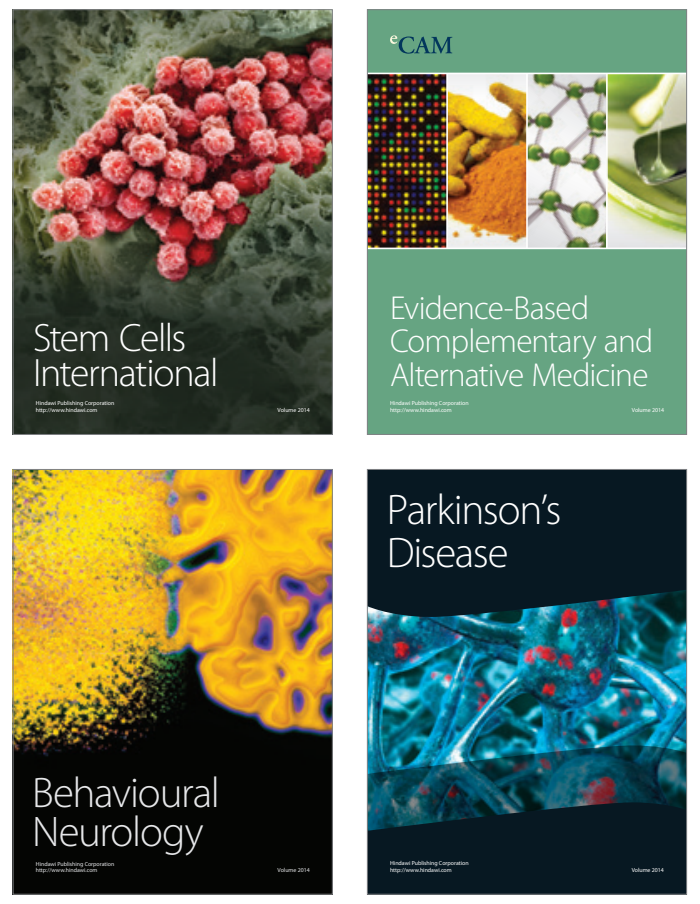
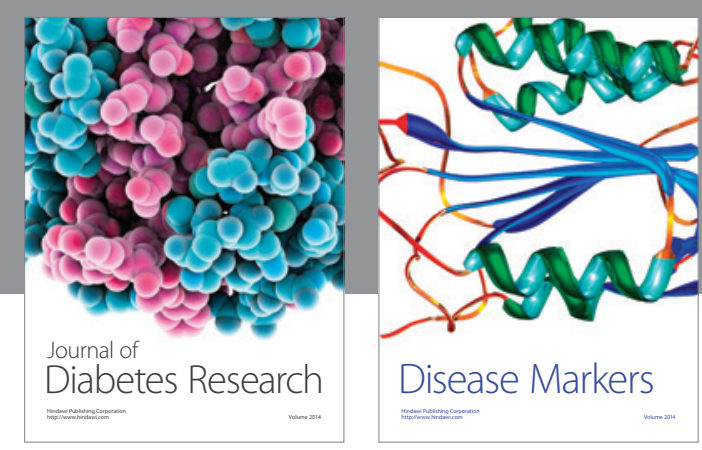

Disease Markers
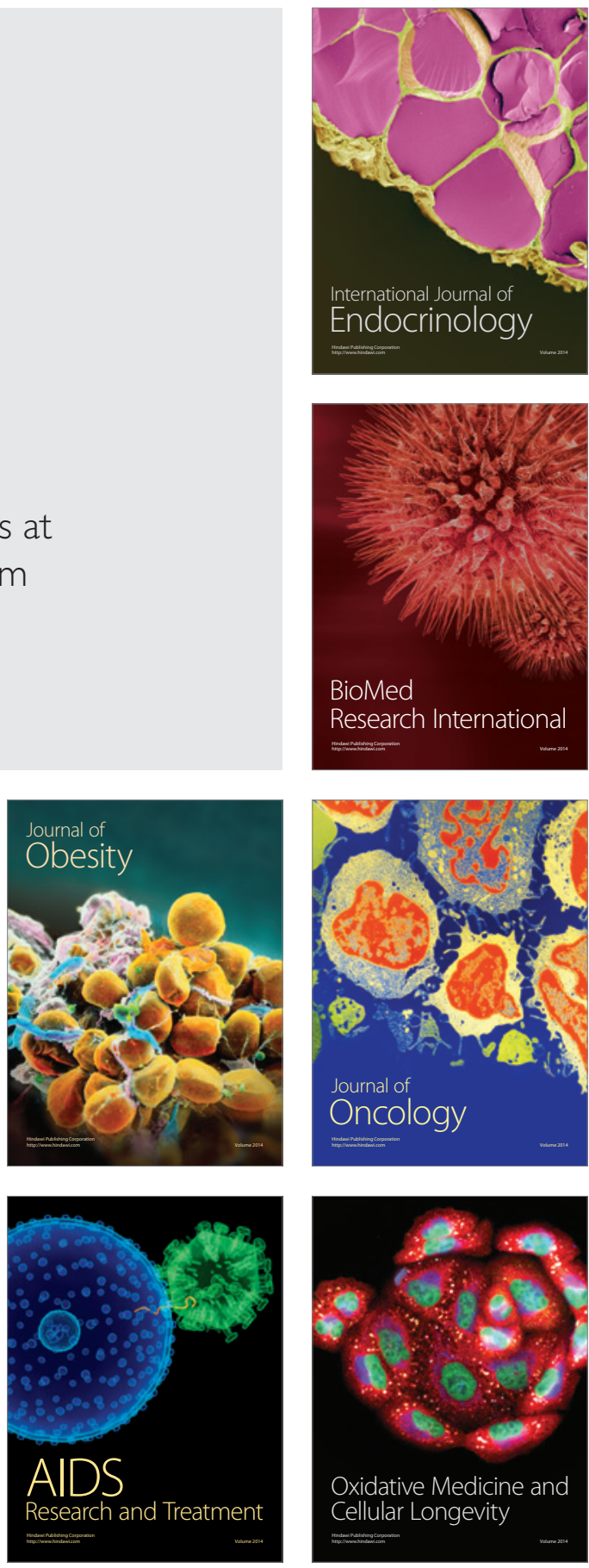